\title{
Morphology, Stability, and Application of Lycopene Microcapsules Produced by Complex Coacervation
}

\author{
Glaucia A. Rocha-Selmi, ${ }^{1}$ Carmen S. Favaro-Trindade, ${ }^{2}$ and Carlos R. F. Grosso ${ }^{1}$ \\ ${ }^{1}$ FEA, University of Campinas, Monteiro Lobato 80, 13083-862 Campinas, SP, Brazil \\ ${ }^{2}$ FZEA, University of Sao Paulo, Duque de Caxias Norte 225, 13635-900 Pirassununga, SP, Brazil
}

Correspondence should be addressed to Glaucia A. Rocha-Selmi; glaucia84@gmail.com

Received 8 May 2013; Revised 26 August 2013; Accepted 12 September 2013

Academic Editor: Joaquin Gomez-Estaca

Copyright (c) 2013 Glaucia A. Rocha-Selmi et al. This is an open access article distributed under the Creative Commons Attribution License, which permits unrestricted use, distribution, and reproduction in any medium, provided the original work is properly cited.

\begin{abstract}
The interest in lycopene has increased in recent years due to studies that associate it with the reduction in risk of developing cardiovascular diseases and cancer. However, due to its high degree of unsaturation, this carotenoid is inclined to isomerize and oxidize during processing and storage, making it difficult to use in the food industry. Microencapsulation can improve this situation, increasing its stability and making incorporation into food formulations possible. Thus, the aim of this study was to microencapsulate lycopene by complex coacervation using gelatin and gum Arabic as the encapsulating agents. The microcapsules were evaluated based on the encapsulation efficiency and their morphology and then submitted to a stability test and applied in cake making. Most of the systems studied presented spherical microcapsules with defined walls. The encapsulation efficiency values were above $90 \%$, and the average diameter of the capsules ranged from 61 to $144 \mu \mathrm{m}$. The stability test showed that microencapsulation offered greater protection to the lycopene as compared to its free form. The application of nonfreeze dried coacervated microcapsules in cake making was satisfactory, but the color transference was low when freezedried coacervated microcapsules were used.
\end{abstract}

\section{Introduction}

Lycopene is a carotenoid that can be incorporated into foods with the purposes of conferring both color and functional characteristics, but it is quite susceptible to isomerization and oxidation [1]. A possible solution to this problem could be the use of microencapsulation, which is the most widely used technique to increase the stability of carotenoids [2].

Complex coacervation consists of spontaneous phase separation by forming an insoluble complex between two or more polymers as a result of electrostatic interactions. The composition and concentration of the wall polymer and environmental conditions such as the $\mathrm{pH}$ and ionic strength, amongst others, are directly related to the efficiency of microcapsule production and to the variability in structure, size, and porosity, amongst other characteristics [3]. Microcapsules produced by coacervation are heat-resistant, possessing excellent controlled-release characteristics based on mechanical stress, temperature, and sustained release [4].
Matioli and Rodriguez-Amaya [1] encapsulated lycopene by freeze drying and spray drying methods. The encapsulating agents were gum Arabic and the gum Ara$\mathrm{bic} /$ maltodextrin pair. The longest half-life time was found for the lycopene encapsulated in gum Arabic and maltodextrin by the freeze drying method.

Matioli and Rodriguez-Amaya [5] studied the microencapsulation of lycopene using cyclodextrins (CD) as the encapsulating agents $(\alpha-\mathrm{CD}, \beta-\mathrm{CD}$, and $\gamma$-CD). Molecular inclusion complexes were formed by $\beta$-CD and $\gamma$-CD but not by $\alpha$-CD. Using the same three types of cyclodextrin for encapsulation, Blanch et al. [6] found that $\beta$-CD was the most favorable encapsulating agent for the stabilization of lycopene at room temperature in the presence of oxygen and light.

Shu et al. [7] and Rocha et al. [8] microencapsulated lycopene by spray drying, using gelatin/sucrose and modified starch, respectively, as the encapsulating agents, and found that the stability of microencapsulated lycopene was significantly higher when compared to the free material. 
Silva et al. [9] encapsulated lycopene by complex coacervation using gelatin and pectin as the encapsulants, but the process did not improve the stability of the pigment. For this reason gelatin and gum Arabic were the choice of encapsulating agents for the present study, since this is one of the most common and extensively used pairs in complex coacervation [10].

The aim of this study was to microencapsulate lycopene by complex coacervation, measure the stability of the carotenoids during storage, incorporate the microcapsules into cakes, and finally evaluate them based on the color transference.

\section{Material and Methods}

2.1. Material. Oil dispersed lycopene (20\% lycopene) (BASF, Lot: $74709816 \mathrm{Kol}$, Germany) was used as the core material, while encapsulating polymers were type A swine gelatin (Gelita South America, Lot: 240P/6, Brazil) and gum Arabic (CNI, Rouen, Lot: IRX49345, France).

\subsection{Methodology}

2.2.1. Microcapsule Production by Complex Coacervation. The methodology for obtaining microcapsules by complex coacervation was adapted from procedures described in [11, 12]. Gelatin and gum Arabic solutions were prepared by dissolution in water at $50^{\circ} \mathrm{C}$. The gelatin solution $(2.5,5$, or $7.5 \%)$ and oil dispersed lycopene (20\% lycopene) were mixed in an Ultra Turrax shaker (IKA T18 Basic, Rio de Janeiro, Brazil) at $10.000 \mathrm{rpm}$ for 3 minutes in order to obtain an emulsion. The emulsion was then mixed with the gum Arabic solution $(2.5,5$, or $7.5 \%)$ by mechanical stirring. The $\mathrm{pH}$ was then adjusted to $4.0 \pm 0.01$ by adding hydrochloric acid $(0.5 \mathrm{M})$ with a dropper. Up to this point in the process, the temperature was monitored and maintained at $50 \pm 3^{\circ} \mathrm{C}$. The system was then cooled to $10^{\circ} \mathrm{C}$ in an ice bath and finally placed in a refrigerator at $3^{\circ} \mathrm{C}$ for 24 hours to complete particle precipitation.

After obtaining the coacervated microcapsules, they were concentrated using a sieve (Mesh of $25 \mu \mathrm{m}$ ). The samples were concentrated in plexiglass plates covered with aluminum foil containing small holes and submitted to slow freezing in a freezer at $-20^{\circ} \mathrm{C}$ for 24 hours. The frozen samples were then freeze-dried (Edwards Pirani 501 Freeze Dryer, West Sussex, UK) for about three consecutive days under the following operational conditions: condenser temperature of $-60^{\circ} \mathrm{C}$, $10^{-1}$ mbar pressure, and a final temperature of $25^{\circ} \mathrm{C}$.

Nine formulations were studied, differing with respect to the total encapsulant (E) $(2.5,5.0$, and $7.5 \%)$ and core (C) concentrations, the latter varying in relation to the total weight of encapsulant $(25,50$, and $75 \%)$. The nine formulations were coded as follows: (1) E2.5/C25; (2) E2.5/C25; (3) E2.5/C75; (4) E5.0/C25; (5) E5.0/C50; (6) E5.0/C75; (7) E7.5/C25; (8) E7.5/C50; and (9) E7.5/C75. The encapsulant ratio was maintained at $1: 1$ for all formulations, since this was the best ratio according to Prata et al. [13], who studied the microencapsulation of vetiver oil by complex coacervation using gelatin and gum Arabic as the encapsulating agents.
2.2.2. Characterization of the Microcapsules According to Their Morphology, Mean Diameter, Rehydration Capacity, and Encapsulation Efficiency (\%EE). An optical microscope (Nikon Eclipse E800, Tokyo, Japan) equipped with the Image Pro Plus 4.0 software was used to evaluate the morphological characteristics of the microcapsules. To calculate the mean diameter, a minimum of 300 particles of each formulation was measured with the aid of this software. The morphology was also evaluated by scanning electronic microscopy (SEM), where the freeze dried samples were fixed to metal tapes adhered on metallic stubs. The stubs were coated with a thin layer of gold in a sputter coater (Balzer SCD50, Lichtenstein, Austria) for 180 seconds with a $40 \mathrm{~mA}$ current. A scanning electronic microscope (Jeol JMS, T300, Tokyo, Japan) with a voltage of $10 \mathrm{kV}$ was used to observe the samples [14].

The rehydration capacity of the microcapsules, determination of their mean diameters, and evaluation of their morphological characteristics by optical microscopy were all carried out in the wet (before freeze drying), freeze dried, and rehydrated forms. Rehydration was carried out by adding water to the freeze dried samples and stirring for 5 minutes, one hour, or 24 hours. The samples were dispersed in water or glycerol (for the freeze dried samples) to capture the images.

The encapsulation efficiency was calculated according to the quantity of lycopene present in the capsules as compared to the quantity initially used to produce them. The lycopene was quantified by spectrophotometry (Biochrom Libra S22 Spectrophotometer-Cambridge, England). The microcapsules were ruptured by an adaption of the method described by Yeo et al. [3]. A $10 \mathrm{~mL}$ aliquot of $0.5 \mathrm{M} \mathrm{NaCl}$ and $10 \mathrm{~mL}$ of $1 \%$ sodium dodecyl sulfate (SDS) were added to the samples (about $10 \mathrm{mg}$ ) and shaken for 1 minute. A $20 \mathrm{~mL}$ aliquot of petroleum ether and $10 \mathrm{~mL}$ of absolute ethyl alcohol were then added and the petroleum ether fraction (which carried the lycopene) withdrawn. The absorption was read at $470 \mathrm{~nm}$, and the lycopene concentration calculated using the method was described in Rodriguez-Amaya [15]. The analyses were carried out in triplicate.

\subsubsection{Determination of the Temperature Stability of the Freeze} Dried Material. The samples (freeze dried microcapsules and lycopene in the free form) were packed into rubberstoppered glass bottles covered with aluminum foil, vacuumsealed and stored at temperatures of 10 and $25^{\circ} \mathrm{C}$ [8]. The lycopene contents were quantified approximately every seven days for a period of 73 days, according to the methodology used to calculate the encapsulation efficiency. On each day of analysis, one bottle of each sample was opened, maintaining the remaining samples out of contact with the oxygen and light. The analyses were performed in triplicate.

2.2.4. Application of the Microcapsules to a Food System. The model system chosen for application of the microcapsules was cake. The cakes were prepared based on the methodology described by Santos et al. [16] and Rocha et al. [8] as follows: (A) with lycopene in the free form, (B) with no lycopene (standard), (C) with coacervated microcapsules, and (D) with freeze dried coacervated microcapsules. 
TABLE 1: Mean diameter and encapsulation efficiency of microcapsules.

\begin{tabular}{lcc}
\hline Formulation & $\begin{array}{c}\text { Mean diameter } \pm \text { standard } \\
\text { deviation }(\mu \mathrm{m})\end{array}$ & $\begin{array}{c}\text { Encapsulation } \\
\text { efficiency }(\%)\end{array}$ \\
\hline 1 & $144 \pm 79^{\mathrm{a}}$ & $99.42 \pm 3.88^{\mathrm{a}}$ \\
2 & $134 \pm 60^{\mathrm{a}}$ & $91.58 \pm 3.42^{\mathrm{c}}$ \\
3 & $144 \pm 98^{\mathrm{a}}$ & $90.73 \pm 3.58^{\mathrm{c}}$ \\
4 & $64 \pm 17^{\mathrm{b}}$ & $97.55 \pm 1.93^{\mathrm{ab}}$ \\
5 & $72 \pm 26^{\mathrm{b}}$ & $97.91 \pm 1.24^{\mathrm{ab}}$ \\
6 & $61 \pm 20^{\mathrm{b}}$ & $99.63 \pm 1.07^{\mathrm{a}}$ \\
7 & - & $93.08 \pm 1.12^{\mathrm{bc}}$ \\
8 & - & $93.33 \pm 4.55^{\mathrm{bc}}$ \\
9 & - & $95.12 \pm 1.57^{\mathrm{b}}$ \\
\hline
\end{tabular}

Different letters in the same column indicate that there was significant difference between samples $(P<0.05)$. Formulations 1: E2.5/C25; 2: E2.5/C25; 3: E2.5/C75; 4: E5.0/C25; 5: E5.0/C50; 6: E5.0/C75; 7: E7.5/C25; 8: E7.5/C50; and 9: E7.5/C75.

To prepare the standard cake (B) two eggs and $150 \mathrm{~g}$ margarine were first beaten together in a domestic mixer (Leco, São Paulo, Brazil). Without stopping to beat the mixture, $240 \mathrm{~g}$ of granulated sugar (União, São Paulo, Brazil) was then added, and subsequently a total of $240 \mathrm{~g}$ of wheat flour (Sol, Fortaleza, Brazil) and $240 \mathrm{~mL}$ of whole milk (Líder, Lobato, Brazil) were added alternately in small aliquots. Finally the mixer was turned off, and 10 grams of baking powder (Royal, Jundiai, Brazil) were added and mixed manually. The mixture was poured into a greased and floured cake pan and baked in a preheated oven for about 40 minutes.

The microcapsules were added to cake formulations (C) and (D) by mixing them with the milk at $50^{\circ} \mathrm{C}$. Lycopene in the free form (formulation (A)) was added to the mix after adding the flour and milk. Formulations (A), (C), and (D) contained the same concentration of lycopene.

The apparent color analysis was carried out by making objective measurements by direct reflection using a colorimeter (Hunter Lab, Color Quest II, Virginia, USA). The readings were made with D65 illumination, a viewing angle with an opening of $10^{\circ}$ and the RSIN mode. For the measurements, each sample was cut into slices about $2 \mathrm{~cm}$ thick and five readings taken at random points [8].

2.2.5. Statistical Analysis. The data were statistically analyzed using the SAS statistical software (Statistic Analysis System), version 8.02, by ANOVA and the Tukey test, at a 5\% significance level.

\section{Results and Discussion}

3.1. Microcapsule Characterization. For all the formulations, a precipitate and a clear supernatant are formed after coacervation. Figure 1 shows optical and electronic microscopic images taken of some of the formulations. Microscopy showed that the microcapsules of formulations 1-6 were spherical, multinucleate, and with defined walls. Formulations 7-9 $(E=7.5 \%)$ differed from the others in relation to
TABLE 2: Mean diameter of formulation 6 moist microcapsules, lyophilized and rehydrated by different periods.

\begin{tabular}{lc}
\hline Condition of the capsules & Mean diameter $(\mu \mathrm{m})$ \\
\hline Lyophilized & $30.82 \pm 7.56^{\mathrm{c}}$ \\
Moist (before lyophilization) & $48.32 \pm 10.95^{\mathrm{a}}$ \\
Rehydrated for 5 min & $44.14 \pm 14.53^{\mathrm{b}}$ \\
Rehydrated for 1 hour & $47.92 \pm 12.95^{\mathrm{a}}$ \\
Rehydrated for 24 hours & $47.84 \pm 12.17^{\mathrm{a}}$ \\
\hline
\end{tabular}

Different letters in the same column indicate significant difference between samples $(P<0.05)$.

their format, since they had no definite form. According to Schmitt et al. [17], an excess of polymer can cause an excess of charge, impairing formation of the complex. In addition, Thies [11] stated that the increase in viscosity caused by a high polymer concentration in the solution could also influence the formation of the microcapsules, decreasing the mobility of the macromolecules and hence the extent of competition, as the solvent molecules became larger.

The mean diameters of the capsules present in formulations 1-6 were calculated, but it was not possible to determine the diameters of formulations 7,8 , and 9 since they did not present the required sphericity. The average diameter of the microcapsules analyzed varied from 61 to $144 \mu \mathrm{m}$ (Table 1). These values were slightly larger than those found by Mendanha et al. [18] when encapsulating hydrolyzed casein by complex coacervation using isolated soy protein and pectin as the encapsulating agents but were in agreement with the expected values for the diameters of coacervates, which can vary from 1 to $500 \mu \mathrm{m}$ [19]. Formulations 1,2 , and 3 ( $E=$ $2.5 \%)$ produced significantly $(P<0.05)$ larger microcapsules than formulations 4,5 , and $6(E=5 \%)$, in which the capsules were smaller but present in larger amounts, indicating that the concentration of the encapsulating agent influenced the size of the capsules. This influence of the concentration of the encapsulating material has been cited in studies which make assumptions about the size of the microcapsules according to the production parameters, such as the ratio of the encapsulating agents, polymer concentrations, amount of core material, stirring rate, cooling rate, and type of drying procedure [20-23].

Apparently the freeze drying process caused no major damage to the morphology of the microcapsules, since rehydration was successful, restoring the spherical shape of the capsules with an appearance similar to that of the moist sample. Prata et al. [13] also observed the continuity of the sphericity of coacervated microcapsules after freeze drying. When comparing the three drying methods (dehydration, spray drying, and freeze drying), Leclercq et al. [24] concluded that freeze drying was the best method for preparing coacervated capsules, with gelatin and gum Arabic as the encapsulating agents. A significant uptake of water by the rehydrated freeze dried samples was also observed, as evidenced by the mean diameters (Table 2), which showed values close to the original sizes of the moist microcapsules before the drying process. 


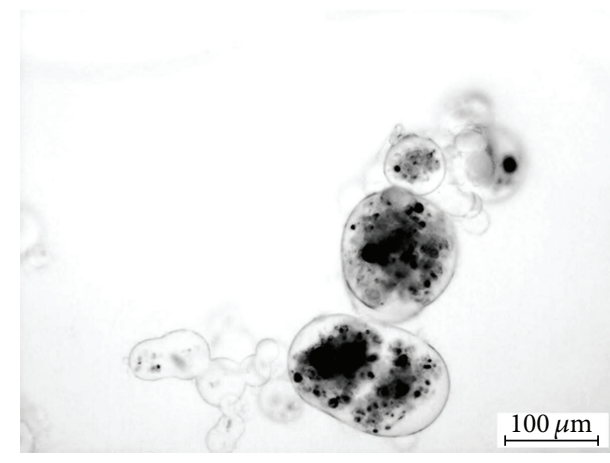

(a)

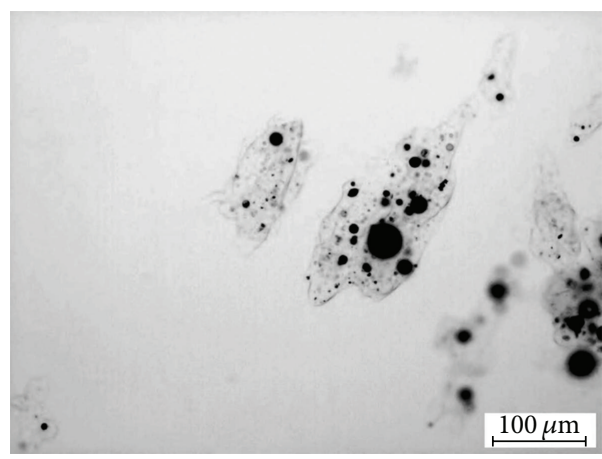

(c)

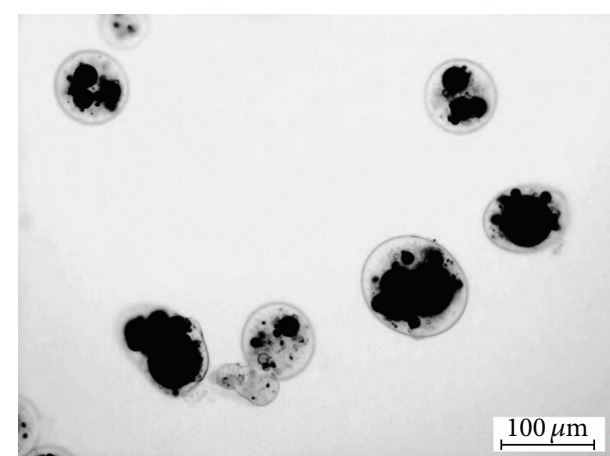

(b)

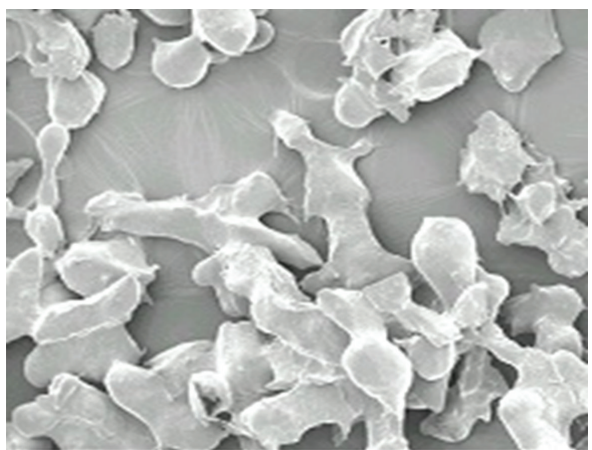

(d)

Figure 1: Micrographs obtained with the optical microscope (a, b, c) and scanning electronic microscope (d) of the lycopene microcapsules: (a, d) formulation 1 (E2.5/C25), (b) formulation 4 (E5.0/C25), and (c) formulation 7 (E7.5/C25).

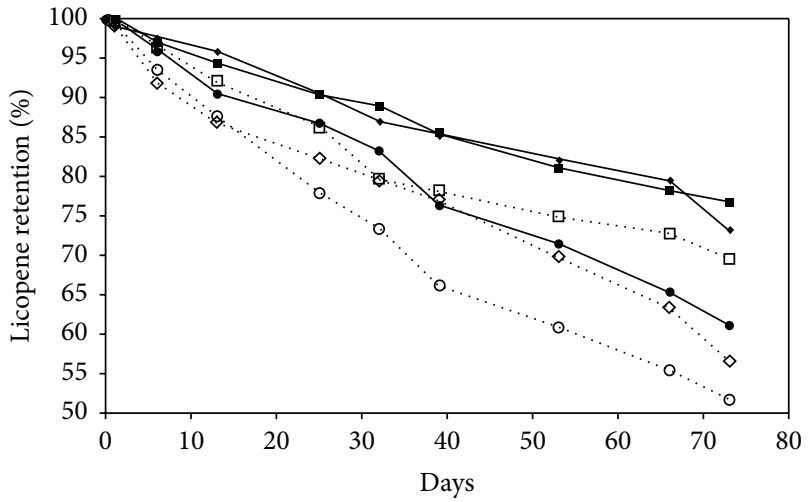

FIGURE 2: Storage stability of free and microencapsulated lycopene during storage at $10^{\circ} \mathrm{C}$ : $(\$) 1(\mathrm{P} 2.5 / \mathrm{R} 25)\left(-0,3391 x+99,474 / R^{2}=\right.$

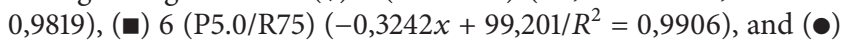
free lycopene $\left(-0,5257 x+99,297 / R^{2}=0,9922\right)$ and during storage at $25^{\circ} \mathrm{C}:(\diamond) 1(\mathrm{P} 2.5 / \mathrm{R} 25)\left(-0,5384 x+97,236 / R^{2}=0,9796\right)$, (口) 6 $(\mathrm{P} 5.0 / \mathrm{R} 75)\left(-0,4203 x+97,947 / R^{2}=0,9505\right)$, and (o) free lycopene $\left(-0,666 x+97,194 / R^{2}=0,9754\right)$.

Table 1 shows the values obtained for encapsulation efficiency. High values are normally found in the literature for the encapsulation efficiency of coacervated capsules $[13,24]$ when gelatin and gum Arabic are used as the encapsulating agents. However, when pectin and soy protein isolate were used as the encapsulating agents to encapsulate propolis and casein hydrolysate, the encapsulation efficiencies were in the range from $66-72 \%$ [25] to $78-91 \%$ [18]. These results confirmed that gelatin and gum Arabic were more efficient encapsulating agents than pectin and soy protein isolate. When lycopene was encapsulated by spray drying, the encapsulation efficiencies were in the range from 21.01 to $29.73 \%$ using modified starch [8], from 12.1 to $82.2 \%$ using gelatin and sucrose [7], and from 25.6 to $87.5 \%$ [26] using gum Arabic, gellan gum, and maltodextrin as the encapsulation material. In view of these results, it is possible to affirm that complex coacervation is a more efficient method to encapsulate lycopene than spray drying. This can be explained by the milder temperatures used in complex coacervation, an important factor for the encapsulation of a highly sensitive compound such as lycopene.

\subsection{Stability of Lycopene in the Free and Microencapsu-} lated Forms. It is important to evaluate the stability of the lycopene, because carotenoids may be destroyed during the processing and storage of foods, and the main cause is enzymatic or nonenzymatic oxidation. Isomerization of transcarotenoids to cisisomers leads to food discoloration and occurs by contact with acids, heat treatment, and light exposure [27].

Table 3 shows the retention of lycopene in formulations 1 and 6 (chosen because they presented the highest encapsulation efficiencies) after 73 days and the corresponding values for the free lycopene at two different temperatures. Lycopene 


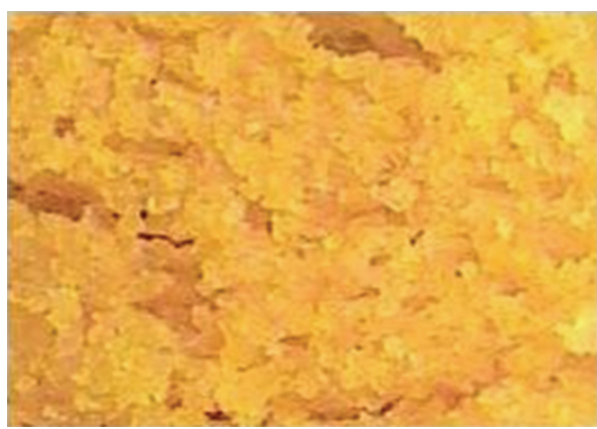

(a)

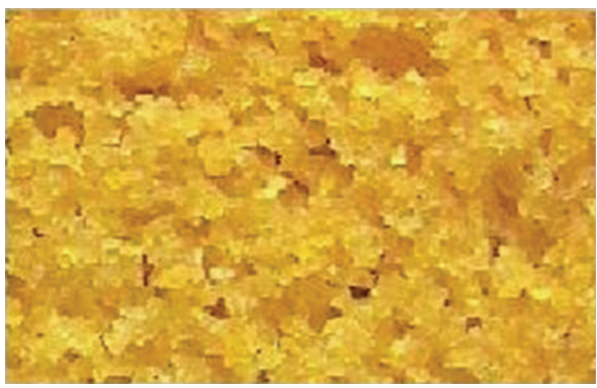

(c)

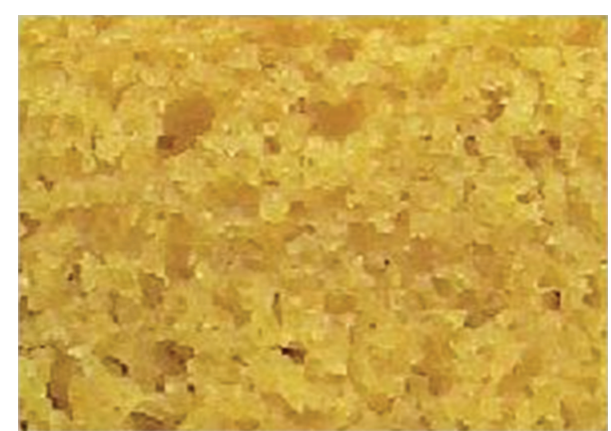

(b)

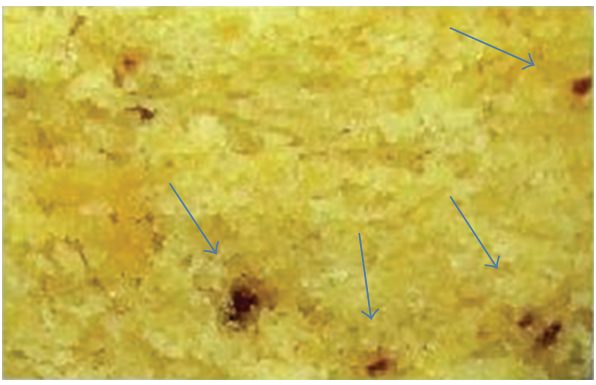

(d)

FIGURE 3: Distribution of lycopene in cakes: (a) free; (b) without lycopene; (c) coacervate; (d) coacervate lyophilized (arrows point to clusters of lycopene).

TABLE 3: Retention of lycopene in microcapsules and in free form after 73 days.

\begin{tabular}{lccc}
\hline Temperature & Formulation & $\begin{array}{c}\text { \% Retention } \\
\text { (encapsulated) }\end{array}$ & $\begin{array}{c}\text { \% Retention } \\
\text { (free) }\end{array}$ \\
\hline $10^{\circ} \mathrm{C}$ & 1 & $73.29 \pm 0.42^{\mathrm{Aab}}$ & $61.18 \pm 0.53^{\mathrm{Ba}}$ \\
$10^{\circ} \mathrm{C}$ & 6 & $76.73 \pm 0.95^{\mathrm{Aa}}$ & $61.18 \pm 0.53^{\mathrm{Ba}}$ \\
$25^{\circ} \mathrm{C}$ & 1 & $56.62 \pm 1.35^{\mathrm{Ac}}$ & $51.82 \pm 2.3^{\mathrm{Ab}}$ \\
$25^{\circ} \mathrm{C}$ & 6 & $69.65 \pm 0.71^{\mathrm{Ab}}$ & $51.82 \pm 2.3^{\mathrm{Bb}}$ \\
\hline
\end{tabular}

Different lowercase letters in the same column indicate that there was significant difference between samples $(P<0.05)$.

Different capital letters in the same row indicate that there was significant difference between samples $(P<0.05)$.

Formulations: 1: P2.5/R25; 6: P5.0/R75.

retention was greatly influenced by storage temperature. For all the formulations studied, as expected the retention was significantly higher when maintained at $10^{\circ} \mathrm{C}$ than at $25^{\circ} \mathrm{C}$, since the lycopene oxidation process is greater at higher temperatures. Under all the conditions studied, the greatest losses were found for the free lycopene, indicating that microencapsulation by complex coacervation offered greater protection to the lycopene. The results followed a linear trend as can be seen in Figure 2, and the choice of a linear fit was confirmed by the high values obtained for the correlation coefficient $\left(R^{2}\right)$ using this fit.

In the study of the stability (in the absence of light at room temperature) of lycopene microencapsulated by spray drying using gum Arabic as the encapsulant, Matioli and RodriguezAmaya [1] found a $50 \%$ loss of lycopene after 18 days. Shu et al. [7] evaluated the stability of lycopene microcapsules encapsulated in gelatin and sucrose by spray drying and stored at $0^{\circ} \mathrm{C}$ in transparent plastic bags and found a loss of about 15\% after 28 days. These performances are inferior to the performance of the formulations studied in the present paper, although the discrepancies could be attributed to the presence of oxygen during storage in the studies by these authors.

Matioli and Rodriguez-Amaya [5] found that lycopene microencapsulated in $\gamma$-cyclodextrin remained stable for 40 days in both the presence and absence of light, when stored in the absence of oxygen at temperatures ranging from 25 to $35^{\circ} \mathrm{C}$. However, this is a much more expensive encapsulating agent than the one used in the present study.

Silva et al. [9] encapsulated lycopene by complex coacervation with gelatin and pectin as the encapsulating agents and evaluated the stability of the free and microencapsulated lycopene by the same methodology used in the present study. After 10 days of storage, they found no significant differences between the concentrations of free and microencapsulated lycopene. This result may indicate that the gelatin/gum Arabic pair was more efficient in protecting the lycopene from degradation than the gelatin/pectin pair.

3.3. The Application of the Microcapsules in a Food System. For the application in cakes, the microcapsules from formulation 6 were used, because they performed better in the stability test.

Rocha et al. [8] studied the use of lycopene microcapsules obtained by spray drying in cakes and analyzed the results of pigmentation according to the coordinate "a." Table 4 
TABLE 4: Values of coordinates "a" for cakes produced with lycopene in different means and without lycopene.

\begin{tabular}{lc}
\hline Sample & Coordinate “a” \\
\hline Free lycopene & $33.65 \pm 0.46^{\mathrm{a}}$ \\
Coacervate & $32.83 \pm 0.37^{\mathrm{a}}$ \\
Coacervate lyophilized & $18.50 \pm 0.27^{\mathrm{c}}$ \\
Without lycopene & $1.70 \pm 0.21^{\mathrm{d}}$ \\
\hline
\end{tabular}

Different letters in the same column indicate significant difference between samples $(P<0.05)$.

shows the values obtained for coordinate "a" for the cake samples. The sample with added moist coacervate presented no significant difference in relation to the cake with added free lycopene. As expected, all the samples differed from the standard cake (without lycopene). In the study by Rocha et al. [8], the free lycopene cake showed a significantly higher value for coordinate "a" than the cake with lycopene microcapsules obtained by spray drying. This result shows that the capsules obtained by complex coacervation have a better capacity to pigment the food system studied than the capsules obtained by spray drying. The variation in lycopene pigmentation can be visualized in the samples shown in Figure 3. There is a homogeneous distribution of the pigment in the samples with nonfreeze dried microcapsules (Figure 3(c)), indicating the effectiveness of the functionality of these encapsulates in the cake pigmentation. The same homogeneous distribution was observed in the sample with free lycopene (Figure 3(a)). However, the freeze dried coacervated microcapsules (Figure 3(d)) showed a less intense pigmentation, heterogeneous distribution, and the presence of lycopene concentrated at some points (shown by arrows). During the preparation of the mix, the microcapsules were not dissolved, and the heat of the oven was not sufficient to break them up completely, and thus the core was not fully released and distributed throughout the cake, which restricts the direct use of freeze dried coacervated microcapsules in this type of application. Adjustments are required for the prior hydration of the freeze dried microcapsules to induce the release of the pigment into the product.

\section{Conclusions}

It is possible to produce microcapsules from oily solutions of lycopene using the complex coacervation technique with gelatin and gum Arabic as the encapsulants.

The freeze drying process was efficient in drying the capsules, since when rehydrated, they recovered their initial size and appearance.

In the stability test, the retention of lycopene was found to be greater in the microcapsules as compared to the free material, indicating the potential of microencapsulation to provide greater protection against degradation of the carotenoid, favoring its application in food formulations.

The nonfreeze dried microcapsules presented good functionality and potential for use in foods, since they were able to release lycopene during preparation of the system studied and to color it homogenously.

\section{Conflict of Interests}

The authors have no conflict of interests with the mentioned commercial identities.

\section{References}

[1] G. Matioli and D. B. Rodriguez-Amaya, "Licopeno encapsulado em goma arábica e maltodextrina: estudo da estabilidade," Brazilian Journal of Food Technology, vol. 5, pp. 197-203, 2002.

[2] I. L. Nunes and A. Z. Mercadante, "Encapsulation of lycopene using spray-drying and molecular inclusion processes," Brazilian Archives of Biology and Technology, vol. 50, no. 5, pp. 893900, 2007.

[3] Y. Yeo, E. Bellas, W. Firestone, R. Langer, and D. S. Kohane, "Complex coacervates for thermally sensitive controlled release of flavor compounds," Journal of Agricultural and Food Chemistry, vol. 53, no. 19, pp. 7518-7525, 2005.

[4] Z. Dong, Y. Ma, K. Hayat, C. Jia, S. Xia, and X. Zhang, "Morphology and release profile of microcapsules encapsulating peppermint oil by complex coacervation," Journal of Food Engineering, vol. 104, no. 3, pp. 455-460, 2011.

[5] G. Matioli and D. B. Rodriguez-Amaya, "Microencapsulação do licopeno com cilclodextrinas," Ciência e Tecnologia de Alimentos, vol. 23, pp. 102-105, 2003.

[6] G. P. Blanch, M. L. R. del Castillo, M. M. Caja, M. PérezMéndez, and S. Sánchez-Cortés, "Stabilization of all-translycopene from tomato by encapsulation using cyclodextrins," Food Chemistry, vol. 105, no. 4, pp. 1335-1341, 2007.

[7] B. Shu, W. Yu, Y. Zhao, and X. Liu, "Study on microencapsulation of lycopene by spray-drying," Journal of Food Engineering, vol. 76, no. 4, pp. 664-669, 2006.

[8] G. A. Rocha, C. S. Fávaro-Trindade, and C. R. F. Grosso, "Microencapsulation of lycopene by spray drying: characterization, stability and application of microcapsules," Food and Bioproducts Processing, vol. 90, no. 1, pp. 37-42, 2012.

[9] D. F. Silva, C. S. Fávaro-Trindade, G. A. Rocha, and M. Thomazini, "Microencapsulation of lycopene by gelatin-pectin complex coacervation," Journal of Food Processing and Preservation, vol. 36, no. 2, pp. 185-190, 2012.

[10] X.-Y. Qv, Z.-P. Zeng, and J.-G. Jiang, "Preparation of lutein microencapsulation by complex coacervation method and its physicochemical properties and stability," Food Hydrocolloids, vol. 25, no. 6, pp. 1596-1603, 2011.

[11] C. Thies, Complex Coacervation. How To Make Microcapsules, Lecture and Laboratory Manual, 1995.

[12] A. Lamprecht, U. F. Schäfer, and C.-M. Lehr, "Characterization of microcapsules by confocal laser scanning microscopy: structure, capsule wall composition and encapsulation rate," European Journal of Pharmaceutics and Biopharmaceutics, vol. 49, no. 1, pp. 1-9, 2000.

[13] A. S. Prata, M. H. A. Zanin, M. I. Ré, and C. R. F. Grosso, "Release properties of chemical and enzymatic crosslinked gelatin-gum Arabic microparticles containing a fluorescent probe plus vetiver essential oil," Colloids and Surfaces B, vol. 67, no. 2, pp. 171-178, 2008.

[14] G. A. Rocha, M. A. Trindade, F. M. Netto, and C. S. FávaroTrindade, "Microcapsules of a casein hydrolysate: production, characterization, and application in protein bars," Food Science and Technology International, vol. 15, no. 4, pp. 407-413, 2009.

[15] D. B. Rodriguez-Amaya, A Guide to Carotenoid Analysis in Food, ILSI Press, Washington, DC, USA, 2001. 
[16] A. B. Santos, C. S. Fávaro-Trindade, and C. R. F. Grosso, "Functionality of microencapsulated paprika oleoresin in arabic gum and rice starch/gelatin," Pesquisa Agropecuária Brasileira, vol. 41, no. 2, pp. 351-354, 2006.

[17] C. Schmitt, C. Sanchez, F. Thomas, and J. Hardy, "Complex coacervation between $\beta$-lactoglobulin and acacia gum in aqueous medium," Food Hydrocolloids, vol. 13, no. 6, pp. 483-496, 1999.

[18] D. V. Mendanha, S. E. M. Ortiz, C. S. Fávaro-Trindade, A. Mauri, E. S. Monterrey-Quintero, and M. Thomazini, "Microencapsulation of casein hydrolysate by complex coacervation with SPI/pectin," Food Research International, vol. 42, no. 8, pp. 10991104, 2009.

[19] C. S. Fávaro-Trindade, S. C. Pinho, and G. A. Rocha, "Microencapsulação de ingredientes alimentícios," Brazilian Journal of Food Technology, vol. 11, no. 2, pp. 103-112, 2008.

[20] A. R. Bachtsi and C. Kiparissides, "Synthesis and release studies of oil-containing poly (vinyl alcohol) microcapsules prepared by coacervation," Journal of Controlled Release, vol. 38, no. 1, pp. 49-58, 1996.

[21] F. M. Menger, A. V. Peresypkin, K. L. Caran, and R. P. Apkarian, "Sponge morphology in an elementary coacervate," Langmuir, vol. 16, no. 24, pp. 9113-9116, 2000.

[22] A. Lamprecht, U. Schäfer, and C.-M. Lehr, "Influences of process parameters on preparation of microparticle used as a carrier system for $\Omega-3$ unsaturated fatty acid ethyl esters used in supplementary nutrition," Journal of Microencapsulation, vol. 18, no. 3, pp. 347-357, 2001.

[23] K. Nakagawa, S. Iwamoto, M. Nakajima, A. Shono, and K. Satoh, "Microchannel emulsification using gelatin and surfactant-free coacervate microencapsulation," Journal of Colloid and Interface Science, vol. 278, no. 1, pp. 198-205, 2004.

[24] S. Leclercq, K. R. Harlander, and G. A. Reineccius, "Formation and characterization of microcapsules by complex coacervation with liquid or solid aroma cores," Flavour and Fragrance Journal, vol. 24, no. 1, pp. 17-24, 2009.

[25] M. P. Nori, C. S. Fávaro-Trindade, S. M. Alencar, M. Thomazini, J. C. C. Balieiro, and C. J. C. Castillo, "Microencapsulation of propolis extract by complex coacervation," LWT: Food Science and Technology, vol. 44, no. 2, pp. 429-435, 2011.

[26] M. E. Rodríguez-Huezo, R. Pedroza-Islas, L. A. PradoBarragán, C. I. Beristain, and E. J. Vernon-Carter, "Microencapsulation by spray drying of multiple emulsions containing carotenoids," Journal of Food Science, vol. 69, no. 7, pp. E351E359, 2004.

[27] D. B. Rodriguez-Amaya, "Effects of processing and storage on food carotenoids," Sight and Life Newsletter, vol. 3, pp. 25-35, 2002. 

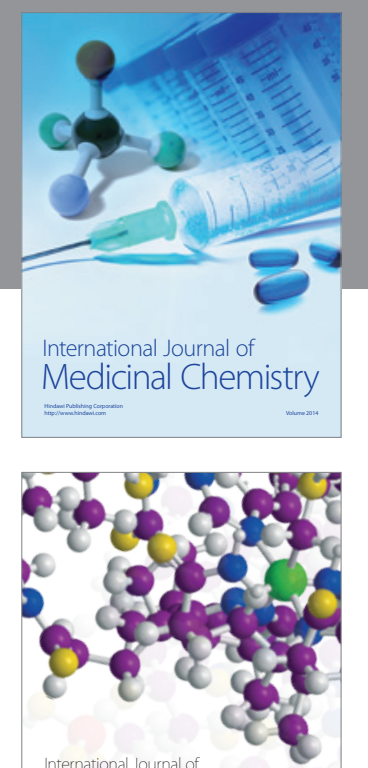

\section{Carbohydrate} Chemistry



The Scientific World Journal
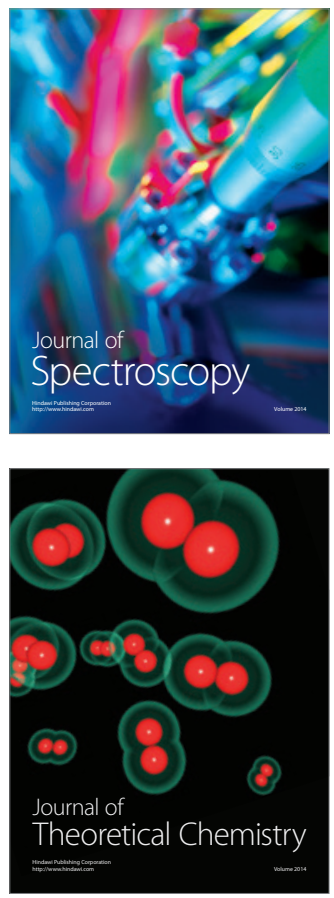
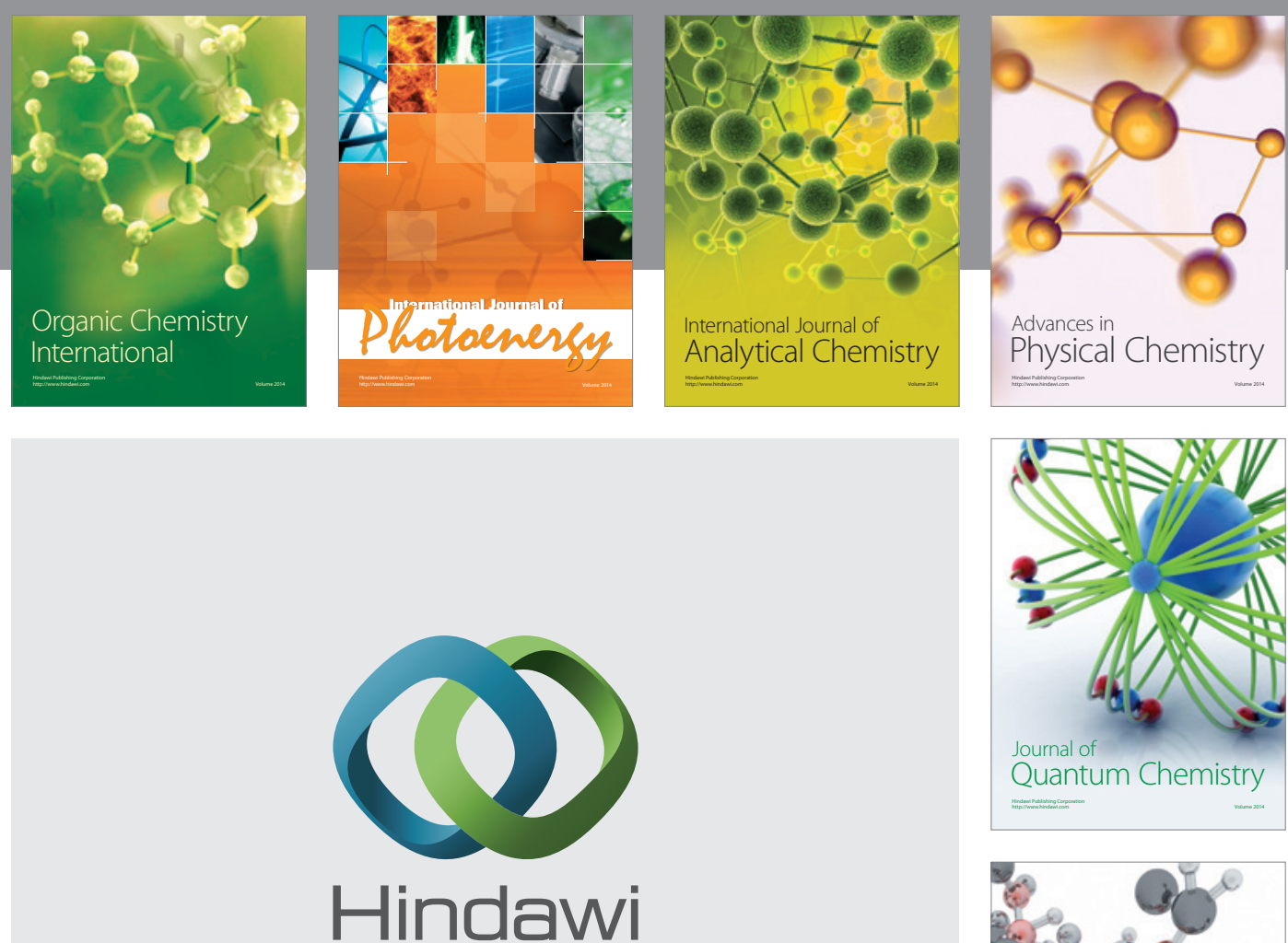

Submit your manuscripts at

http://www.hindawi.com

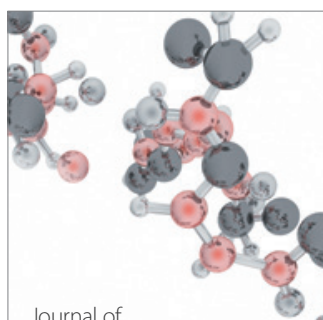

Analytical Methods

in Chemistry

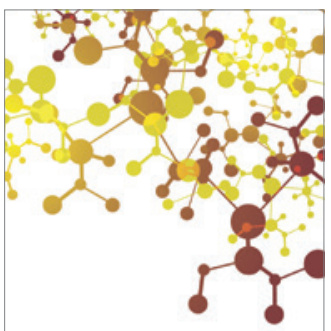

Journal of

Applied Chemistry

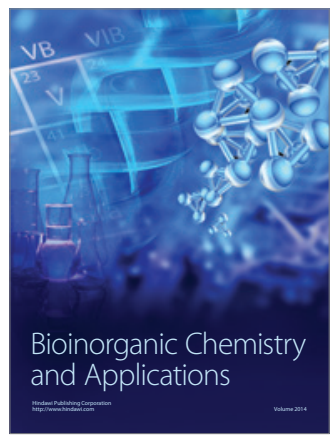

Inorganic Chemistry
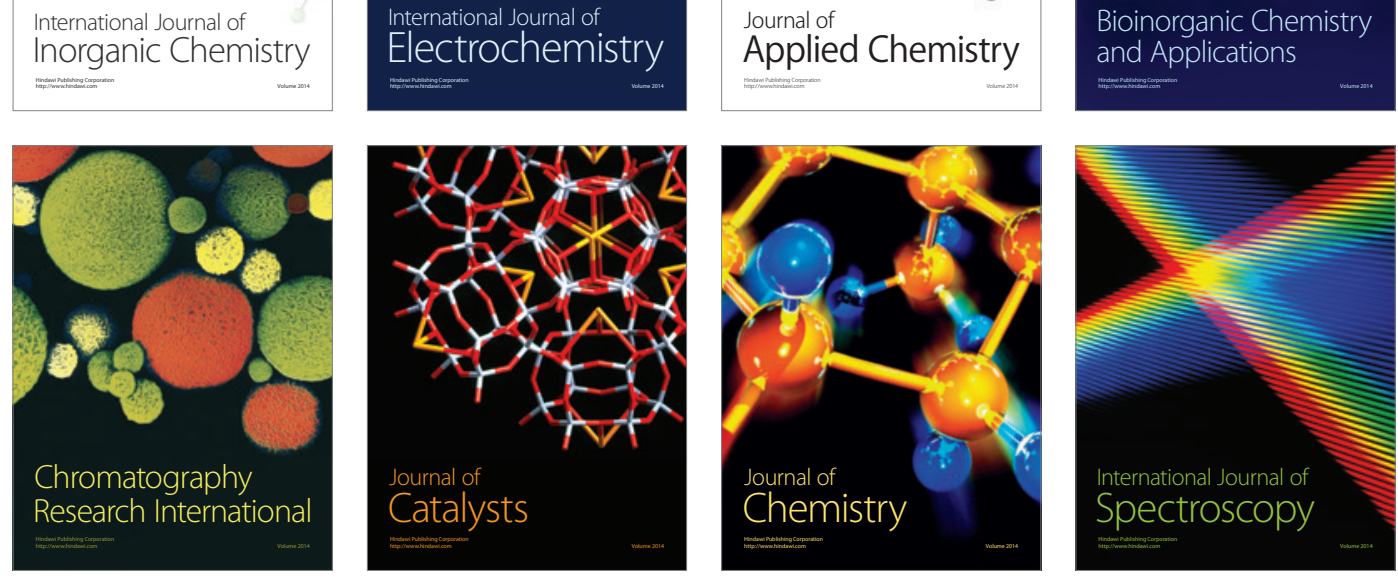